This document was prepared in conjunction with work accomplished under Contract No. DE-AC09-96SR18500 with the U.S. Department of Energy.

This work was prepared under an agreement with and funded by the U.S. Government. Neither the U. S. Government or its employees, nor any of its contractors, subcontractors or their employees, makes any express or implied: 1 . warranty or assumes any legal liability for the accuracy, completeness, or for the use or results of such use of any information, product, or process disclosed; or 2 . representation that such use or results of such use would not infringe privately owned rights; or 3 . endorsement or recommendation of any specifically identified commercial product, process, or service. Any views and opinions of authors expressed in this work do not necessarily state or reflect those of the United States Government, or its contractors, or subcontractors. 


\title{
A Family of Peroxo-titanate Materials Tailored for Optimal Strontium and
}

\section{Actinide Sorption}

\author{
May Nyman $*^{*}$ and David T. Hobbs ${ }^{{ }^{*}}$ \\ ${ }^{¥}$ Sandia National Laboratories, P.O. Box 5800 MS 0754, Albuquerque, NM87185-0754 \\ ${ }^{\S}$ Savannah River National Laboratory, Washington Savannah River Company, Aiken, SC 29808 \\ *correspondence: mdnyman@sandia.gov \\ david.hobbs@srnl.doe.gov
}

\begin{abstract}
Achieving global optimization of inorganic sorbent efficacy, as well as tailoring sorbent specificity for target sorbates would facilitate increased wide-spread use of these materials in applications such as producing potable water or nuclear waste treatment. Sodium titanates have long been known as sorbents for radionuclides; ${ }^{90} \mathrm{Sr}$ and transuranic elements in particular. We have developed a related class of materials, which we refer to as peroxo-titanates: these are sodium titanates or hydrous titanates synthesized in the presence of or treated post-synthesis with hydrogen peroxide. Peroxo-titanates show remarkable and universal improved sorption behavior with respect to separation of actinides and strontium from Savannah River Site (SRS) nuclear waste simulants. Enhancement in sorption kinetics can potentially result in as much as an order of magnitude increase in batch processing throughput.

Peroxo-titanates have been produced by three different synthetic routes: post-synthesis peroxidetreatment of a commercially produced monosodium titanate, an aqueous-peroxide synthetic route, and an isopropanol-peroxide synthetic route. The peroxo-titanate materials are characteristically yellow to orange, indicating the presence of protonated or hydrated Ti-peroxo species; and the chemical formula can be generally written as $\mathrm{H}_{\mathrm{v}} \mathrm{Na}_{\mathrm{w}} \mathrm{Ti}_{2} \mathrm{O}_{5} \cdot\left(\mathrm{xH}_{2} \mathrm{O}\right)\left[\mathrm{yH}_{\mathrm{z}} \mathrm{O}_{2}\right]$ where $(\mathrm{v}+\mathrm{w})=2, \mathrm{z}=0-2$, and total volatile species accounts for $25-50 \mathrm{wt} \%$ of the solid. Further enhancement of sorption performance is achieved by processing, storing and utilizing the peroxo-titanate as an aqueous slurry rather than a dry powder, and post-synthesis acidification. All three synthesis modifications; addition of hydrogen peroxide, use of a slurry form and acidification can be applied more broadly to the optimization of other metal oxide sorbents and other ion separations processes.
\end{abstract}




\section{Introduction}

Inorganic sorbents for ion separations are applied in both industry and the public sector for sequestration of hazardous species, recovery of precious metals, and improvement of water quality and purity. Some specific applications include removal of radionuclides from nuclear wastes ${ }^{1-5}$ and contaminated waste sites, ${ }^{1,6}$ water softening, ${ }^{7}$ arsenic removal from domestic water supplies, ${ }^{8-11}$ treatment of industrial wastewater, ${ }^{12,13}$ and scavenging trace metals from catalytic reaction products (i.e. synthesis of pharmaceuticals) ${ }^{14}$. Natural and synthetic clays, ${ }^{15,16}$ zeolites $^{16,17}$ and other nanoporous frameworks, ${ }^{18-20}$ micro- ${ }^{21,22}$ and meso- ${ }^{23}$ porous materials, and hydrous metal oxides ${ }^{24,25}$ have all been shown to be effective in metal separation applications. Mechanisms of ion sorption can broadly be described as ion exchange on surfaces (esp. with surface $\mathrm{H}^{+}$) or in layers, channels, or pores; or electrostatic binding of ions to oppositely-charged surface sites. Understanding and optimizing selectivity, kinetics, and capacity of sorbent materials for specific ions under varying chemical environments is the ultimate challenge for researchers who seek improved performance of ion exchange materials.

While the counterpart organic phases for ion sequestration such as calixarenes enjoy the advantage of precise atomic control over size and functional groups that define the ion sequestering cavity, they suffer from lack of stability in harsh chemical or radiological environments, such as those found in nuclear wastes. Contrarily, precise design of inorganic sorbents is somewhat hampered by thermodynamic or kinetic limitations of metal oxide systems; but inorganic sorbents are superior in their ability to withstand harsh media. Organic sequestering reagents are generally difficult to synthesize with multiple step and low yield processes whereas inorganic sorbents such as metal oxides are produced in high yields by simple reactions, and also occur naturally (zeolites, clays). Liu et al. ${ }^{26,27}$ introduced a class of sorbents which features metal oxide scaffolds functionalized with self-assembled monolayers of sorbate-specific ligands. While this elegant approach provides the rugged substrate of inorganic materials with the selectivity or specificity of organic functional groups; it still lacks the simplicity and stability that is preferred for some applications such as nuclear waste processing or water treatment.

Control over specificity or selectivity of inorganic sorbent materials is in fact a challenge that has infrequently been demonstrated. Size matching the targeted sorbate to the sorption site in a porous phase is one approach to tailoring ion selectivity, exemplified by crystalline silicotitanate $\left(\mathrm{CST}, \mathrm{Na}_{2} \mathrm{Ti}_{2} \mathrm{SiO}_{7} \cdot 2 \mathrm{H}_{2} \mathrm{O}\right)$. 
CST is a zeotype phase with high selectivity for $\mathrm{Cs}^{+}$(for sequestration of radioactive ${ }^{137} \mathrm{Cs}$ ) due to the ideal size-matching of the exchange sites in the pores. ${ }^{28,29}$ Furthermore, the selectivity of CST for $\mathrm{Cs}^{+}$is improved by substituting $\mathrm{Nb}^{5+}$ into $25 \%$ of the framework $\mathrm{Ti}^{4+} \cdot{ }^{28}$ The improved selectivity is rationalized by the charge-compensating replacement of $25 \%$ of the channel $\mathrm{Na}^{+}$with water, which both provides additional coordination and thus stabilization of $\mathrm{Cs}^{+}$, and also results in less repulsion between neighboring cations in the channel. ${ }^{30,31}$ Furthermore, the replacement of $\mathrm{Ti}$ with $\mathrm{Nb}$ slightly increases the unit cell size, and the larger tunnel more readily accommodates transport of cesium to binding sites. ${ }^{31}$ However, the drawback of a size-exclusion approach such as present in the 1-dimensional tunnels of CST is slow sorption kinetics and relatively low ion exchange capacity.

We are interested in developing optimized, titanate-based inorganic sorbents without necessarily adding great expense or difficulty to production. Although we anticipate more widespread applicability of our optimized sorbents, we specifically target removal of ${ }^{90} \mathrm{Sr}$ and alpha-emitting radionuclides, principally ${ }^{238,239,240} \mathrm{Pu}$ and ${ }^{237} \mathrm{~Np}$, from the highly alkaline wastes that derive from reprocessing of irradiated fuel and target materials at the Savannah River Site (SRS).

Presently, the SRS has identified monosodium titanate (MST) for Sr and actinide separations in the Actinide Removal Process (ARP) facility and the Salt Waste Processing Facility (SWPF) via a batch contact method. $^{32}$ Monosodium titanate, which was first developed by Dosch $^{33}$ at Sandia National Laboratories as a radionuclide sorbent, is a poorly crystalline, layered sodium titanate with an approximate chemical formula of $\mathrm{HNaTi}_{2} \mathrm{O}_{5} \cdot \mathrm{xH}_{2} \mathrm{O}$. SRNL researchers modified the synthesis of the MST to produce a spherical morphology with $\sim 0.5-2$ micron diameter tailored for use at the SRS. ${ }^{32}$ A more crystalline version of sodium titanate known as sodium nonatitanate $\left(\mathrm{Na}_{4} \mathrm{Ti}_{9} \mathrm{O}_{20} \cdot \mathrm{xH}_{2} \mathrm{O}\right)$ has also been assessed to have suitable sorption capabilities for nuclear waste treatment applications. ${ }^{1,2,34}$ SrTreat $^{\mathrm{TM}}$ is a commercially available titanate-based ion exchanger that has noteworthy selectivity for strontium in nuclear waste media. $^{35}$

Titanate-based materials offer the advantages of robustness in harsh chemical and radioactive environments, ease of synthesis, and effective sorption capabilities in a variety of media including acidic, basic, neutral; and high or low ionic strength. While all variations of these titanate sorbents have been shown to have sufficient strontium-removal capabilities, they lack suitable kinetics and selectivity for 
actinide separations (Pu in particular) for optimal operation in treating the strongly alkaline and high ionic waste solutions at the SRS.

We report here a general synthetic strategy for any titanate-based sorbent (including mixed metal titanates such as silicotitanates) that results in significantly improved sorption characteristics. Addition of hydrogen peroxide, either during formation of the titanate material or as a post-treatment step results in formation of a peroxo-titanate, ${ }^{36}$ which is identified by its characteristic yellow color, indicative of hydrated or protonated Ti-peroxo bonds. ${ }^{37,38}$ Further improvements in sorption capabilities are imparted by 1) post-syntesis acidification of the peroxo-titanate materials and 2) utilizing the sorbents as slurries rather dry powders.

Three synthetic routes for peroxo-titanate materials are reported in this paper, all which show significantly improved sorption performance over their related titanate materials. The three synthetic routes explored in this study include: 1) post-synthesis peroxide treatment of MST, 2) isopropanolperoxide synthesis, and 3) aqueous-peroxide synthesis. Synthesis, characterization and radionuclide separation studies for the peroxo-titanate materials are described in this report. Preliminary evaluation of the peroxide-modified MST materials for treatment of SRS high-level waste demonstrates remarkable improvement in processing efficiency. The increased capacity and kinetics exhibited by the peroxotitanates suggest that the use of these materials should increase the throughput of the processing facilities resulting in significant operating and life-cycle cost savings. 


\section{Experimental}

\section{Synthesis of peroxo-titanates}

\section{Post-synthesis peroxide treatment of MST slurry.}

MST slurry (Optima Chemical Group Ltd, Lot \# 00-QAB-417) containing 14.8 wt\% MST solids, $\mathrm{pH} \sim 10.8$ ) slurry was used for all post-treatment preparations. Table 1 provides a summary of the peroxide treatment conditions. Variations in treatment conditions included $\mathrm{H}_{2} \mathrm{O}_{2}: \mathrm{Ti}$ ratio, $\mathrm{pH}$ of the MST slurry, contact time of the slurry with the peroxide solution, and post-peroxide treatment $\mathrm{pH}$ adjustment. Generally, 10 grams of MST slurry was stirred in a small glass beaker and the pH of the MST slurry was decreased using $0.1-2$ molar nitric acid solutions. Hydrogen peroxide solution(30 wt \%) was added dropwise to the MST slurry to obtain the desired $\mathrm{H}_{2} \mathrm{O}_{2}$ :Ti ratio. Upon addition of the hydrogen peroxide, the white MST immediately changes to a bright yellow color and is accompanied by the evolution of oxygen gas bubbles. Some dissolution of the MST occurred during this process, as indicated by the yellow color of the aqueous portion of the slurry. After the appropriate contact time, the peroxide remaining in solution was removed by subsequent filtering and washing the solids with fresh deionized, distilled water, without complete drying of the sample. For experiments \#13P and 14P, a final $\mathrm{pH}$ adjustment was made by adding $0.1 \mathrm{M}$ nitric acid solution until reaching the desired $\mathrm{pH}$.

\section{Isopropanol-peroxide route.}

These syntheses were derived from the MST synthesis developed by Hobbs et al. ${ }^{32}$ Synthesis parameters varied for these experiments include $\mathrm{H}_{2} \mathrm{O}_{2}$ :Ti ratio, mixing time, acidic or neutral $\mathrm{H}_{2} \mathrm{O}$ for hydrolysis and condensation of alkoxides, and post-synthesis $\mathrm{pH}$ adjustments. These synthesis parameters are summarized in Table 1. The peroxo-titanate phases from these syntheses were either filtered and airdried to obtain a dry powder or converted to an aqueous slurry and, if appropriate, $\mathrm{pH}$-adjusted as described above. A typical preparation is described in detail as follows. Titanium isopropoxide (TIPT, $\operatorname{Ti}\left(\mathrm{OC}_{3} \mathrm{H}_{7}\right)_{4}, 1$ gram, $3.5 \mathrm{mmol})$ and sodium methoxide $\left(\mathrm{NaOCH}_{3}, 0.095 \mathrm{~g}, 1.75 \mathrm{mmol}\right)$ are placed in a $20 \mathrm{ml}$ glass vial containing a stirbar in an inert atmosphere box to give a 1:2 Na:Ti ratio. The vial is capped and transferred outside the glovebox where $9 \mathrm{ml}$ isopropanol is pipetted into the vial. The mixture is stirred until a clear, 
pale yellow solution is obtained. In a separate vial, $30 \mathrm{wt} \% \mathrm{H}_{2} \mathrm{O}_{2}$ solution (i.e. $1.2 \mathrm{~g}, 10.5 \mathrm{mmol} \mathrm{H}_{2} \mathrm{O}_{2}$ for 3:1 $\mathrm{H}_{2} \mathrm{O}_{2}$ :Ti ratio) is combined with one gram of water or one gram of 0.1 molar nitric acid solution (referred to neutral or acidic respectively in Table 1). This aqueous solution is then added to the isopropanol solution and a yellow precipitate forms instantaneously; stirring is continued for the predetermined time. Typical yield is $0.35-0.40$ grams of dry yellow powder. Cautionary note: this reaction evolves gas from decomposition of the $\mathrm{H}_{2} \mathrm{O}_{2}$ - do not tightly cap vials during the reaction; pressure build-up will break the vials!

\section{Aqueous-peroxide Route, Basic (exp. \#1A-14A).}

This synthetic procedure can generally be described as dissolution of titanium alkoxide in a hot, strongly alkaline- $\mathrm{H}_{2} \mathrm{O}_{2}$ solution followed by precipitation of the titanate material. Variables in these syntheses include molar concentration of sodium hydroxide, ratio of $\mathrm{H}_{2} \mathrm{O}_{2}: \mathrm{Ti}$, and post-acidification of the product. Other experimental parameters investigated included; utilizing the final sorbent product as a powder vs. a slurry, a secondary post-treatment with $\mathrm{H}_{2} \mathrm{O}_{2}$, use of $\mathrm{TiCl}_{4}$ instead of titanium ispopropoxide as a Ti-precursor, and reverse order of $\mathrm{Ti}$ and $\mathrm{H}_{2} \mathrm{O}_{2}$ addition. A typical synthesis is described as follows (experiment \# 1A). Sodium hydroxide solution (3 molar, $75 \mathrm{ml}$ ) is heated and stirred in a $125 \mathrm{ml}$ Erlenmeyer flask. When the solution reaches around $60{ }^{\circ} \mathrm{C}$, six grams $(21 \mathrm{mmol})$ of TIPT is added from a pipette to the hot solution, whereupon a white precipitate immediately forms. Approximately 40 grams of $30 \mathrm{wt} \% \mathrm{H}_{2} \mathrm{O}_{2}$ solution is added slowly, around 10 grams at a time. The addition of the $\mathrm{H}_{2} \mathrm{O}_{2}$ results in dissolution of the white precipitate to obtain a bubbly, clear, bright yellow solution. Continued stirring and heating of the solution (approximately $10-60$ minutes) results in precipitation of a yellow solid. Either a dry powder is obtained by vacuum filtration and rinsing with DI water, or a slurry is obtained by multiple cycles of decanting the reaction solution and replacing it with fresh DI water. Cautionary note: In strongly basic solutions, $\mathrm{H}_{2} \mathrm{O}_{2}$ decomposes rapidly and exothermically with gas evolution. Be alert for solution boil-over.

Synthesis from $\mathrm{TiCl}_{4}($ exp. \#8A). Sodium hydroxide solution $(25 \mathrm{ml}, 16 \mathrm{M} \mathrm{NaOH})$ is placed in a $100 \mathrm{ml}$ flask. While stirring at room temperature, $45 \mathrm{ml}$ of 0.09 molar $\mathrm{TiCl}_{4}, 20 \% \mathrm{HCl}$ aqueous solution (Aldrich) 
is added via syringe. A grayish precipitate is observed. Twenty grams of $30 \mathrm{wt} \% \mathrm{H}_{2} \mathrm{O}_{2}$ solution is slowly added. Over the course of peroxide addition, the solution becomes clear yellow and then precipitates a greenish-yellow solid, which is collected by vacuum filtration. Yield $=0.49$ grams. Cautionary note: this reaction is very exothermic; it should be carried out in a fumehood and executed with caution.

$\underline{\text { Synthesis from } \mathrm{TiCl}_{4}}$ with reverse addition of reagents (exp. \# $-\underline{7 \mathrm{~A})}$.

Twenty grams of $30 \mathrm{wt} \% \mathrm{H}_{2} \mathrm{O}_{2}$ solution is placed in a $100 \mathrm{ml}$ Erlenmeyer flask. Seventeen $\mathrm{ml}$ of 0.09 molar $\mathrm{TiCl}_{4}, 20 \% \mathrm{HCl}$ aqueous solution is added via syringe, resulting in a bright orange solution. While stirring, 3 molar $\mathrm{NaOH}$ solution is added dropwise. After about $10 \mathrm{ml}$ is added, a yellow precipitate was formed and no more $\mathrm{NaOH}$ was added. Yield: 0.17 grams.

\section{Second post-synthesis peroxide treatment (exp.\#12A \& 13A)}

After a yellow precipitate is formed from the TIPT/ $\mathrm{NaOH} / \mathrm{H}_{2} \mathrm{O} / \mathrm{H}_{2} \mathrm{O}_{2}$ mixture (basic aqueous peroxide route), the precipitate is left to settle. The liquid is decanted, more DI water is added, the mixture is stirred and this process is continued until the decanted liquid no longer appears yellow. More DI water is added to bring the total volume to around $200 \mathrm{ml}$. Ten grams $30 \mathrm{wt} \% \mathrm{H}_{2} \mathrm{O}_{2}$ solution is added and the slurry stirred for about twenty minutes (note: prolonged stirring results in complete dissolution of the precipitate!). The decantation process is repeated as described above. Centrifugation of the slurry prior to decanting was utilized in this case since the solids settle more slowly after the second peroxide treatment.

\section{Aqueous-peroxide Route, Acidic (exp. \#14A-17A).}

\section{Exp. \# 14A and 15A.}

Six $\mathrm{ml}$ of 15.8 molar concentration nitric acid solution was added to $94 \mathrm{ml}$ of DI water to obtain $100 \mathrm{ml}$ of $\sim 1$ molar nitric acid solution. For 15A, 0.6 grams $(7.0 \mathrm{mmol})$ of sodium nitrate was dissolved in the nitric acid solution. While heating and stirring, 2 grams TIPT $(7.0 \mathrm{mmol})$ was added dropwise to form a deep red, clear solution. Each solution was boiled down to $\sim 20 \mathrm{~mL}$. Sodium hydroxide solution (2 molar) was added gradually the red color faded and a yellow solid precipitated. The final $\mathrm{pH}$ for exp. \# 14A was 8.8 and the final $\mathrm{pH}$ for exp. \# 15A was 11.7. 


\section{$\underline{\text { Acidification of Peroxo-titanates. }}$}

Powder: Approximately 0.2 grams of peroxo-titanate powder is placed in $150 \mathrm{ml}$ of water and stirred. Nitric acid solution ( 0.1 molar) is slowly added dropwise until the desired $\mathrm{pH}$ is reached (generally 2, 4 or 5). The powder is collected by vacuum filtration. Slurry: The as-prepared slurry is stirred while adding 0.1 molar nitric acid solution dropwise until the desired $\mathrm{pH}$ is obtained. The $\mathrm{pH}$-adjusted slurry requires no further modification.

\section{Characterization of Peroxotitanates.}

\section{Instrumentation.}

The peroxo-titanates were characterized by a number of techniques including powder X-ray diffraction (XRD), Scanning Electron Microscopy (SEM), thermogravimetric analysis-differential thermal analysis (TGA-DTA), infrared spectroscopy (IR), compositional analysis (Na and Ti), high resolution transmission electron microscopy (HR-TEM), and surface area analysis. X-Ray diffraction was performed with a Bruker D8 Advance Diffractometer in Bragg-Brentano geometry with Ni-filtered $\mathrm{Cu}-\mathrm{K} \bullet$ radiation. Samples were examined with a JEOL JSM-6300V scanning electron microscope (SEM) equipped with a Link GEM Oxford detector and IRIDIUM IXRF Systems software for EDAX analysis. Transmission electron microscopy (TEM) was done with a Philips CM 30 TEM operating at $300 \mathrm{kV}$ accelerating voltage, and powder samples were salted onto a carbon-coated copper TEM grid.

Thermal analysis was performed with a TA Instruments SDT 2960 simultaneous TGA-DTA under nitrogen flow with a heating rate of $5{ }^{\circ} \mathrm{C} / \mathrm{min}$. Infra-red spectra $\left(400-4000 \mathrm{~cm}^{-1}\right)$ were recorded on a Perkin-Elmer Spectrum GX FTIR using the KBr pellet method. Surface area measurements were obtained by BET analysis of adsorption isotherms on a Quantachrome Autosorb-1 or Micromeretocs ASA2010 Porosimeter Analyzer. Nitrogen was used as the adsorbate, and samples were outgassed under vacuum at room temperature over night prior to analysis. Micropore surface areas were determined by T-plot analysis and average pore diameter and pore volume were obtained via $\mathrm{BJH}$ analysis of desorption isotherms. 


\section{Compositional Analysis.}

Sodium and titanium content for each sample was determined by Inductively Coupled Plasma Atomic Emission Spectroscopy using a Perkin Elmer Optima 3000 instrument. Samples were first dissolved in 3M sulfuric acid solution and diluted 20:1 in 2\% nitric acid solution.

\section{Performance Testing with Simulated Waste Solution.}

Testing of combined strontium and actinide removal performance was carried out at the Savannah River National Laboratory (SRNL) using the simulated waste solution composition as shown in Table 2 including plutonium, uranium, and neptunium in addition to ${ }^{85} \mathrm{Sr}$. Strontium and actinide removal testing occurred at $25 \pm 3{ }^{\circ} \mathrm{C}$ at an equivalent MST solids concentration of $0.4 \mathrm{~g} / \mathrm{L}$. Standard sampling of the test bottles occurred at 4, 24 and 168 hours of contact. Additional interim samplings between 4 and 24 hours were taken for select tests to provide additional data on adsorption kinetics. Samples were filtered through 0.45-micron syringe filters (nylon membrane) to remove MST solids. Gamma spectroscopy measured the

${ }^{85} \mathrm{Sr}$ and neptunium content. ${ }^{85} \mathrm{Sr}$ activities were decay corrected to the time of sampling. We measured the ${ }^{238} \mathrm{Pu}$ and ${ }^{239,240} \mathrm{Pu}$ content by radiochemical separation of the plutonium from uranium and neptunium followed by alpha counting of the extracted plutonium. Sorption tests using the baseline MST sample (Optima Batch \#00-QAB-417) and blank tests were run in parallel for comparison to the peroxo-titanate sorption tests and confirm that loss of strontium and actinides did not occur by sorption onto container walls or filter surfaces.

\section{Results and Discussion}

\section{Synthesis and Characterization of Peroxo-titanates.}

All peroxo-titanates synthesized in this study have the characteristic yellow color indicative of a titanium-peroxo specie that is protonated or associated with water protons. ${ }^{37,38}$ Generally, deeper yelloworange hues were observed for acidified peroxo-titanate powders and slurries, and peroxo-titanate materials precipitated under alkaline conditions are paler yellow in color. For the isopropanol-peroxide syntheses, earlier studies indicated that base catalysis for hydrolysis and condensation of the alkoxide (as apposed to 
neutral or acidic---Expt. Numbers 1I-13I) produced a less effective sorbent, so this route was not pursued further in this study.

We generally obtained $\sim 80 \%$ yield or greater for the isopropanol-peroxide synthetic routes. Lower yields were obtained by the basic aqueous-peroxide routes due to partial dissolution of the product. We observed decreasing yields in the aqueous-peroxide route with increasing hydroxide concentration. Post-synthesis acidification and second peroxide treatments also decreased the product yields; again due to partial dissolution of the sorbent in these conditions. Although we observe dissolution of the peroxotitanate materials in these harsh synthetic or post-synthetic treatment media, the peroxo-titanates do not exhibit significant solubility in the highly basic, high ionic strength simulant solutions. This suggests that excess hydrogen peroxide in the synthesis mixture is largely responsible for dissolution of the titanate powders.

\section{Structure and Morphology of Peroxo-titanates.}

Generally, all the peroxo-titanate materials reported here appear amorphous by powder X-ray diffraction. Scanning Electron Microscopy (SEM) images of the three types of peroxo-titanate materials; peroxide treated Optima MST, peroxo-titanates from isopropanol media, and peroxo-titanates from aqueous media (both acidic and basic) are shown in Figure 1. The peroxide-treated MST materials appear identical to the original MST materials; spherically-shaped (0.5-2 micron diameter) with a layered morphology on the particle surfaces. The peroxo-titanates synthesized in isopropanol media are largely featureless at the resolution of the SEM. The peroxo-titanates synthesized in aqueous $\mathrm{NaOH}$ consist entirely of small, entangled fibers. The acidic-aqueous route produced smooth, uniform spherical particles with a diameter similar to that of MST.

Transmission electron microscopy (TEM) was necessary to obtain more detailed morphological and possibly structural information from all three types of peroxo-titanates, given the poor long-range atomic ordering and the small scale of the observed morphological features. TEM images of crosssectioned (via microtoming) MST spherical particles were reported by Duff et al. ${ }^{39}$ The TEM images

revealed a fibrous and layered material with a layer-spacing around $6.3 \AA^{39}{ }^{39}$ However, this morphology resided only on the outer portion of the particles. The interior of the MST had no visible features. 
The TEM and high resolution (HR) TEM images of peroxo-titanates produced by the basic aqueous syntheses reveal a layered structure within the fibers with a layer spacing of around 7-8 (Figure 2). The fibers are actually better described as ribbons and are generally less than 10 nanometers thick and 40 nanometers wide. The layer spacing observed in both the rims of the MST particles and in the fibrous peroxo-titanate materials formed via the aqueous-peroxide synthesis is similar to that observed in the more crystalline sodium nonatitanate. ${ }^{40}$ This suggests that these aqueous peroxo-titanate materials (as well as the outer portion of MST) are similar in structure to that of sodium nonatitanate, but with much less long-range order or smaller particle size, as observed by their respective powder X-ray diffraction spectra.

Sodium nonatitanates, which are processed hydrothermally at $>100{ }^{\circ} \mathrm{C}$ for several days ${ }^{40}$ usually have sufficient long-range order to observe the layer spacing by X-ray powder diffraction. The MST and peroxo-titanates from the aqueous-peroxide route, both processed around $80{ }^{\circ} \mathrm{C}$ for $1-2$ hours, are amorphous by X-ray powder diffraction, but basal lattice planes can be easily observed and measured by HR-TEM. The peroxo-titanates from the isopropanol-peroxide route are processed at room temperature, and no crystalline features are observable by TEM.

\section{Composition of Peroxo-titanates.}

The sodium:titanium ratios and wt.\% volatile species for the dried peroxo-titanate materials are compiled in Table 1. Generally, more weight loss due to volatile species is observed in post-acid treated samples. This is a result of replacement of sodium with hydrated protons $\left(\mathrm{H}_{3} \mathrm{O}^{+}, \mathrm{H}_{5} \mathrm{O}_{2}^{+}\right.$, etc. $)$. The replacement of sodium with protons is also reflected in the compositions, with Ti:Na ratios ranging from 340; compared to values closer to 2 for the parent material. Peroxide treatment of MST (1P-15P) in acidic media also reduced the amount of sodium in the sorbent. Generally, a post-synthesis acidification or peroxide treatment at $\mathrm{pH} \sim 2-4$ resulted in a material with $\mathrm{Ti}: \mathrm{Na}>20$.

Since these peroxo-titanate materials are amorphous and, therefore, poorly defined, we can described their chemical formulae only generally as: $\mathrm{H}_{\mathrm{v}} \mathrm{Na}_{\mathrm{w}} \mathrm{Ti}_{2} \mathrm{O}_{5} \cdot\left(\mathrm{xH}_{2} \mathrm{O}\right)\left[\mathrm{yH}_{\mathrm{z}} \mathrm{O}_{2}\right]$ where $(\mathrm{v}+\mathrm{w})=2$. For peroxo-titanates synthesized under neutral or basic conditions, $v \sim \mathrm{W} \sim 1$. For acid-treated peroxo-titanates, $\mathrm{v}>\mathrm{w}$. The specie in square brackets is peroxide, which is most likely coordinated to the titanium and may be present as $\mathrm{O}_{2}{ }^{2-}, \mathrm{HO}_{2}{ }^{-}$, or $\mathrm{H}_{2} \mathrm{O}_{2}(\mathrm{z}=0-2)$. 
The number of protons associated with the peroxide increases with increased acidification of the sample, as indicated by the deepening of the yellow hue. Representative TGA-DTA (thermogravimetrydifferential thermal analysis) plots are shown in Figure 3. Generally, total weight loss varied from $25 \%$ to 50\%. Figure 3a compares MST to peroxide-modified MST. The TGA-DTA plots showed a distinct weight loss event around $600{ }^{\circ} \mathrm{C}$ that is observed in virtually all of the peroxo-titanate materials that have

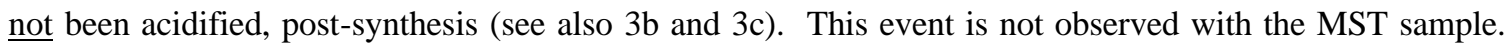
We attribute this event to the loss of the deprotonated peroxide groups.

Loss of protonated peroxide groups in the acidified peroxo-titanates appears to take place at a lower temperature, since for these acidified samples there is more extensive weight loss below $300{ }^{\circ} \mathrm{C}$, and the weight-loss event at $600{ }^{\circ} \mathrm{C}$ is not apparent. This is logical because protonated peroxo-groups have lower charge, are not likely to be as tightly bound to $\mathrm{Ti}$ as the de-protonated peroxo groups and, therefore, are volatilized at a lower temperature. The weight-loss event at $600{ }^{\circ} \mathrm{C}$ is accompanied by an exothermic phase change, as indicated by the DTA spectra (most apparent in 4a and 4c), and the baseline MST also has this exothermic event at $600{ }^{\circ} \mathrm{C}$. In the acidified peroxo-titanate samples, the exothermic event occurs at $400{ }^{\circ} \mathrm{C}(5 \mathrm{~b}$ and $5 \mathrm{c})$. This phase change is most likely crystallization of $\mathrm{TiO}_{2}$ (anatase), which is observed in powder X-ray diffraction spectra of the sample, post TGA-DTA analysis.

\section{Peroxo-titanate Performance for Sr, Np, and Pu Sorption.}

The first set of results discussed is presented as normalized decontamination factors (DF). Decontamination factor is a unitless value defined as the ratio of the original sorbate concentration in solution (before treatment) to the concentration after contact with the sorbent. Normalization is achieved by dividing the decontamination factor of peroxo-titanate by the decontamination factor for the baseline MST. Therefore, if the sorbent has a normalized DF $>1$, it is more effective than the baseline MST. Average $\mathrm{Sr}, \mathrm{Pu}$, and $\mathrm{Np} \mathrm{DF}$ values measured with the simulated waste solution (Table 2) contacted with MST for four hours are 64, 4.8 and 1.3, respectively.

The bar graphs in Figure 4 summarize the normalized $\mathrm{Sr}, \mathrm{Np}$ and $\mathrm{Pu} \mathrm{DF}$ values for the peroxidemodified MST samples (yellow), the peroxo-titanates from the aqueous-synthesis (blue), and the peroxotitanates from the isopropanol-synthesis (green); each with 4-hour contact time with the simulated waste 
solution. The red line across each graph represents the baseline MST performance,which by definition is unity. In general, every peroxo-titanate sorbent out-performed or matched the performance of MST for $\mathrm{Sr}$, $\mathrm{Pu}$ and Np removal. The peroxide-treated MST showed more consistent performance for the different sorbent preparations than those synthesized from the aqueous-peroxide or isopropanol-peroxide routes. This is predominantly due to the wider range of synthesis parameters explored for the aqueous-peroxide and isopropanol-peroxide synthetic routes; especially preparation of dry powders in addition to slurries.

Sorption was generally better for the slurries (10I-13I and 10A-17A) than the analogous powder samples (1I-9I and 1A-9A). However, this trend was more evident for $\mathrm{Pu}$ and $\mathrm{Sr}$ than for $\mathrm{Np}$ (discussed below). Acidification of the peroxo-titanate as a post-synthesis step usually resulted in enhanced performance (esp. for $\mathrm{Sr}$ and $\mathrm{Pu}$ ); for instance, see 6P vs. 13P, 10I vs. 12I, and 12A vs. 13A. However, the drawbacks of acidification include an additional processing step and loss of sorbent due to partial dissolution.

Figure 5 provides a summary of the top two performing sorbents of each of the three peroxotitanate preparation types and the three radionuclides. Again, the data is based on 4-hour DF values, normalized to MST. The most marked improvements over MST sorption capabilities are for Pu sorption, followed by Sr sorption, and comparably moderate improvements were observed for $\mathrm{Np}$ sorption.

Peroxo-titanates prepared by the aqueous route were the top two performers for each radionuclide. More specifically, each of the six aqueous-route peroxo-titanate sorbents highlighted in this graph is a slurry, with the exception of sample 7A, for Np sorption. Sample 13A was the best sorbent for $\mathrm{Sr}$ and $\mathrm{Np}$, and the second-best for Pu. This preparation method however, involves three steps: initial precipitation of the peroxo-titanate, second post-synthesis peroxide treatment and final acidification. Therefore, use in on an industrial scale would require optimization of the synthesis process to minimize material loss by dissolution at each step.

Use of titanium chloride instead of the titanium alkoxide, inverse order of reagent addition and reduction of Ti-concentration (exp \# 6A-9A) generally did not produce superior sorbents with the exception of exp. \# 7A for Np. Np sorption as it relates to sorbent preparation and characterization was counter to every trend observed for $\mathrm{Sr}$ and $\mathrm{Pu}$ sorption. In general (Figure 4) the peroxo-titanates prepared from isopropanol-peroxide route were better sorbents for $\mathrm{Np}$, but poorer sorbents for $\mathrm{Sr}$ and $\mathrm{Pu}$. The slurry 
sorbents were not consistently better for $\mathrm{Np}$ than the analogous dry powder samples, nor were those samples prepared in acidic conditions or acidified post-synthesis.

Further details concerning the disparate sorption behavior of $\mathrm{Np}$ can be observed in Figure 6. In this study, we compared $\mathrm{Np}, \mathrm{Sr}$, and Pu sorption kinetics for several dry-powder peroxo-titanate samples, along with the baseline MST slurry. These data predominately illustrate the effectiveness of a slurry sorbent compared to a dry powder sorbent in the case of $\mathrm{Sr}$ and $\mathrm{Pu}$, and visa versa for $\mathrm{Np}$. The three peroxo-titanates compared to baseline MST in this figure are 1) peroxo-titanate powder from an aqueous synthesis (1A), 2) a peroxo-titanate powder from an isopropanol synthesis (1I), and 3) peroxide-modified MST (6P), filtered and used as a dry powder. At two hours solution contact time, the baseline MST slurry had adsorbed more Sr than 2 of the 3 peroxo-titanate powders. However, with increased contact time (170 hours), the three peroxo-titanate powders have removed more strontium than the baseline MST slurry.

The data for plutonium uptake is similar. At two hours, the peroxo-titanate powders only slightly out-perform the baseline MST slurry. At 24 hours, the three powder samples have removed more Pu than the baseline MST slurry; and at 170 hours, two of the three powders show significantly better Pu removal data than the baseline MST slurry, and the third powder shows comparable performance to MST slurry.

Np sorption shows a different trend, with one powder sample (from the isopropanol preparation) showing significantly better performance at 2 hours, and optimal performance for the powder samples at 24 hours. However, at 150 hours, the aforementioned peroxo-titanate from the isopropanol preparation has rereleased some neptunium back into solution.

Figure 7 provide plots of solution concentrations of strontium and plutonium upon contact with 0.1 and $0.2 \mathrm{~g} / \mathrm{L}$ MST; both baseline and peroxide-treated MST. The peroxo-titanate results are the average of duplicate tests for each of three peroxo-titanate samples. The three peroxo-titanate samples were prepared by the post-synthesis peroxide addition method (exp. \# 14P) at a larger scale (25 g versus $1.5 \mathrm{~g}$ for exp. \# 1P $-15 \mathrm{P}$ listed in Table 1). Error bars in these figures are the single standard deviation of the six values for the peroxide-modified MST samples, the pooled single standard deviation of the six control samples taken over the entire test and the analytical uncertainty reported for each sample measurement in the baseline MST test. 
These tests show excellent reproducibility for the peroxo-titanate samples prepared at the larger scale and improved performance compared to the baseline MST. For strontium adsorption, doubling the amount of both baseline and peroxide-modified MST resulted in proportional increase in strontium removal. However, the peroxide-modified samples removed more strontium than the baseline samples. Most of the strontium removal occurs during the first two hours. The similarity of the four curves (in fact, two are overlapping) suggests that the strontium adsorption mechanism and the type of strontium sorption site does not change for MST upon peroxide modification. However, the number of available or accessible sites for strontium does increase upon peroxide modification.

The uptake of plutonium by MST and peroxide-modified MST shows differing behavior. Again, the peroxide-modified MST exhibits overall improved Pu sorption rate and capacity over that of the baseline MST. The initial Pu sorption during the first two hours is significant for all four tests. However, while $\mathrm{Pu}$ concentration in solution continues to decrease dramatically for the peroxide-modified MST up to 24 hours, the sorption rate drops off for the baseline MST. Doubling the amount of baseline MST does not result in increased total $\mathrm{Pu}$ sorption near equilibrium (170 hours), which suggests that at $0.2 \mathrm{~g} \mathrm{MST/L}$, the baseline MST is saturated with respect to plutonium. However, doubling the amount of peroxide-modified MST does result in increased removal of Pu from solution. These results suggest the peroxide-modified MST has more Pu sorption sites available than baseline MST and the sorption mechanism and/or type of Pu coordination site does differ from that of baseline MST. Characterization and comparison of the Pu and Sr, as well as Np coordination sites in baseline $\mathrm{MST}^{39}$ and peroxide-modified MST are currently underway using XAFS (X-ray absorption fine structure spectroscopy) and vibrational spectroscopies (infrared and Raman).

\section{Relationship between Peroxo-titanate Characteristics and Sorption Behavior.}

This investigation has revealed several important factors for optimizing sodium titanate sorbents for the removal of radionuclides from strongly alkaline nuclear wastes. Perhaps more importantly, the characteristics of the peroxo-titanates responsible for improved performance in these studies may be applied generally for other inorganic metal oxide sorbents, different target sorbates, and alternative sorption media. The most important findings include; 1) peroxo-titanate sorbents prepared or modified with 
hydrogen peroxide are universally superior to titanates prepared without hydrogen peroxide, 2) peroxotitanate samples prepared, modified or post-treated with acid are superior to their neutral or basic counterparts, and 3) drying sodium titanate sorbents at any time during the preparation or modification is deleterious to sorbent performance. Any of these points might be argued to be simply an effect of producing and retaining increased surface area, as well as more reactive surfaces. However, the poorly ordered nature of these sorbents challenges characterization of sorbate complexation, and we believe coordination of sorbates by peroxo-ligands may in fact contribute to enhanced sorption behavior.

Hydrogen peroxide plus acid or base, are good mineralizing solutions for titania. Therefore partial dissolution of the oxide upon exposure to these reagents can produce porosity and accessibility to sorption sites. For the isopropanol-peroxide syntheses and peroxide modification of MST, the combination of base and peroxide produced poorer performing sorbents than the analogous acidic or neutral treatments. Perhaps this is related to the different mechanisms of hydrolysis, condensation and precipitation of oxides in acidic vs. basic environments. Acidic conditions favor hydrolysis and, thus, the formation of high surface area, protonated powders, whereas basic conditions favor condensation and, therefore, produces more monolithic, deprotonated solids with low surface area. ${ }^{41}$

We measured surface area of several peroxo-titanate samples, and these results along with normalized DF values for $\mathrm{Sr}, \mathrm{Pu}$ and $\mathrm{Np}$ are listed in Table 3 (sample IDs correspond with those in Table 1). Regarding the first five dry powder samples, the striking difference in the performance is the actinide DFs: 5A has considerably more surface area and is far superior for $\mathrm{Pu}$ and $\mathrm{Np}$ sorption, but more comparable to the other samples for $\mathrm{Sr}$ removal. The main difference between 5A and the other four samples is a post-synthesis acidic treatment (see Table 1). The increased surface area may be a result of this $\mathrm{pH}$ adjustment (due to the mineralizer effect).

The improved actinide sorption may be linked simply to increased surface area and porosity, but probably also related to the nature of the Ti-peroxo species stabilized under acidic conditions, since there was not a similar improvement in Sr sorption. Regarding the other samples, baseline MST, and samples prepared according to the conditions used in Test \# 14P (MST treated with 3:1 $\mathrm{H}_{2} \mathrm{O}_{2}$ :Ti ratio at $\mathrm{pH}=7$, followed by post-synthesis pH-4 adjustment); the surface areas are much increased compared to the baseline MST, corresponding with universal improvement in DF values. Another difference between the 
MST and treated MST samples is the pore size. The average pore size went from around $215 \AA$ in the baseline MST to $30 \AA$ in the peroxide-modified MST. Likely the $215 \AA$ pores is inter-particle space and the 30 pores Å represent porosity or accessible layering within the titanate material.

In the case of an ion exchange mechanism of sorption (i.e. exchange of $\mathrm{Na}^{+}$or $\mathrm{H}^{+}$for $\mathrm{Sr}^{2+}$ ), the acid forms of the sorbents have an advantage over the sodium forms, which may also contribute to the superior performance of sorbents post-treated with acid or synthesized in acidic media. That is, the hydronium ion is smaller than the hydrated sodium cation and, therefore, can exchange-out from the titanate layers more readily, especially in the highly caustic, waste solutions that contain 1.3 molar in free hydroxide concentration (see Table 2). It has been observed in other ion exchange materials that the protonated form has higher selectivity and faster exchange kinetics than alkali forms. ${ }^{42,43}$

We expect a sorbent that has never been dried to also have a more reactive surface and higher surface area. The surface oxygen sites of an oxide in water should be coordinatively saturated by protonation from the aqueous environment. On the other hand, an oxide that is dried will form bonds between surfaces to stabilize these reactive sites and, thus, lose both surface area and reactive sites for exchange. Returning a dry powder to an aqueous environment can reverse the process and regenerate reactive surfaces (albeit slowly), which is likely the phenomenon being observed in figure 7. The peroxotitanates are poorer or comparable sorbents to the baseline MST slurry at two hours contact time, but exceed MST performance with prolonged contact time. On the other hand, sorption by the MST slurry slows down significantly beyond two hours. In summary, the uptake kinetics of a sorbent is much reduced by converting a slurry form to a dry powder, but not necessarily the equilibrium sorption capacity and selectivity.

Finally we come to the issue of the peroxo species serving as ligands for the strontium and actinide sorbates. The peroxo ligand can exist as $\mathrm{O}_{2}^{2-}, \mathrm{HOO}^{-}$, or $\mathrm{H}_{2} \mathrm{O}_{2}$ and can be bound to titanium side-on or end-on. ${ }^{38}$ The ratio of protonated to non-protonated peroxo ligands likely increases with increasing acidity of the synthesis or post-treatment solutions, also evidenced by the color of the sorbent. Stable peroxo-actinide (predominantly uranium and neptunium) complexes are reported in both aqueous solutions and solid phases, including naturally occurring minerals for uranium. ${ }^{44-48}$ Therefore, it is not unreasonable to expect these complexes to form between a sorbent containing peroxo ligands and sorbed actinides, thus 
contributing to the increased affinity of peroxo-titanates for actinides. As mentioned prior, we are currently investigating the chemical environment of these sorbed actinides using XAFS and vibrational spectroscopies to determine if the peroxo groups have a significant role in binding of these sorbates.

\section{Conclusions}

We have developed a new class of titanate sorbents referred to as peroxo-titanates by three different synthetic methods. The peroxo-titanates exhibit improved performance compared to existing sodium titanate materials for the separation of strontium and actinides from highly alkaline and high ionic strength solutions. Testing also indicated that improved performance of these materials occurs when the peroxo-titanates are acidified and maintained in a fully hydrated form (e.g., as aqueous slurries). We believe the synthetic routes described in this paper can be extended to other transition metal-oxides sorbent systems, which we are actively investigating.

Finally, when Dosch first identified the prototype sodium titanate as a metal sorbent in the mid70's, he noted its affinity for removing a whole host of metals including lanthanides, alkaline earths, precious metals, and transition metals. ${ }^{33}$ He also noted efficacy in various media including acidic and basic aqueous solutions. Given the improved performance of the peroxo-titanates to separate strontium and actinides in simulated nuclear waste solutions, we have confidence that peroxo-titanates will exhibit improved separation characteristics for a variety of metal types and conditions. These studies along with understanding the mechanism of peroxo-titanate sorption are ongoing.

Acknowledgements: This work was funded by the Department of Energy, Office of Environmental Management by grants from the Office of Cleanup Technologies and the Office of Biological and Environmental Research in the Office of Science by a grant from the Environmental Management Science Program. Savannah River National Laboratory is operated by the Washington Savannah River Company for the U. S. Department of Energy's Office of Environmental Management under Contract DE-AC0996SR18500. Sandia National Laboratories is a multiprogram laboratory operated by Sandia Corporation, a Lockheed Martin Company, for the U.S. Department of Energy's National Nuclear Security Administration 
under Contract DE-AC04-94AL85000. The authors thank Drs. Tom Headley and Chuck Hills (SNL) for the TEM and HR-TEM analyses and Drs. Ralph White and Chuck Holland, University of South Carolina, Department of Chemical Engineering, for selected surface area and porsimetry analyses. We also thank Dr.

David DiPrete, Ms. Ceci DiPrete and Mr. Curtis Johnson for the radiochemical analyses as well as Ms.

Mona Blume and Ms. Kimberly Wyzsynski for perfoming the sorption tests at SRNL.

\section{References}

(1) Sylvester, P.; Clearfield, A. Solvent Extraction and Ion Exchange 1998, 16, 1527-1539.

(2) Sylvester, P.; Clearfield, A. Seperation Sci. Technol. 1999, 34, 2539-2551.

(3) Kumar, S. S.; Sivaiah, M. V.; Venkatesan, K. A.; Krishna, R. M.; Murthy, G. S.; Sasidhar, P. J. Radioanal. Nucl. Chem. 2003, 258, 321-327.

(4) Behrens, E. A.; Sylvester, P.; Clearfield, A. Environ. Sci. Technol. 1998, 32, 101-107.

(5) Song, Y. J.; Jiang, L. Q.; Zhao, A. M.; Jin, Q. X.; Song, D. K. J. Radioanal. Nucl. Chem. 1997, 222, 75-80.

(6) Marinin, D. V.; Brown, G. N. Waste Management 2000, 20, 545-553.

(7) Cinar, S.; Beler-Baykal, B. Water Science and Technology 2005, 51, 71-77.

(8) Dixit, S.; Hering, J. Environ. Sci. Technol. 2003, 37, 4182-4189.

(9) Manna, B.; Dasgupta, M.; Ghosh, U. C. J. Water Supply Res. Tech.-Aqua 2004, 53, 483-495.

(10) Lenoble, W.; Laclautre, C.; Deluchat, W.; Serpaud, B.; Bollinger, J. C. J. Hazardous Mater. 2005, 123, 262-268.

(11) Lackovic, J. A.; Nikolaidis, N. P.; Dobbs, G. M. Environ. Eng. Sci. 2000, 17, 29-39.

(12) El-Kamash, A. M.; Zaki, A. A.; Geleel, M. A. E. Journal of Hazardous Materials 2005, 127, 211220.

(13) Hui, K. S.; Chao, C. Y. H.; Kot, S. C. Journal of Hazardous Materials 2005, 1-3, 89-101.

(14) Garrett, C. E.; Prasad, K. Adv. Synth. Catal. 2004, 346, 889-900.

(15) Scheidegger, A. M.; Strawn, D. G.; Lamble, G. M.; Sparks, D. L. Geochim. Cosmochim. Acta 1998, 62, 2233-2245.

(16) Bailey, S. E.; Olin, T. J.; Bricka, R. M.; Adrian, D. D. Water Research 1999, 33, 2469-2479.

(17) Kesraouiouki, S.; Cheeseman, C. R.; Perry, R. J. Chem. Tech. Biotech. 1994, 59, 121-126.

(18) Walcarius, A.; Ganesant, V. Langmuir 2006, 22, 469-477.

(19) Wang, X. L.; Gao, Q. M.; Wu, C. D.; Hu, J.; Ruan, M. L. Microporous and Mesoporous Mater. 2005, 85, 355-364.

(20) Pinnavaia, T. J. Mater. Chem. 1995, 245, 283-300.

(21) Clearfield, A.; Wang, Z. K. J. Chem. Soc. Dalton Trans. 2002, 2937-2947.

(22) Rocha, J.; Lin, Z. Micro- Mesopor. Miner. Phases 2005, 57, 173-201.

(23) Moller, K.; Bein, T. Chem. Mater. 1998, 10, 2950-2963.

(24) Moller, T.; Clearfield, A.; Harjula, R. Microporous and Mesoporous Mater. 2002, 54, 187-199.

(25) Moller, T.; Harjula, R.; Kelokaski, P.; Vaaramaa, K.; Karhu, P.; Lehto, J. J. Mater. Chem. 2003, 13, 535-541.

(26) Fryxell, G. E.; Lin, Y.; Fiskum, S.; Birnbaum, J. C.; Wu, H. Environ. Sci. Technol. 2005, 39, 1324-1331.

(27) Fryxell, G. E.; Liu, J.; Mattigod, S. Materials Technology 1999, 14, 188-191.

(28) Anthony, R. G.; Dosch, R. G.; Philip, C. V., U.S. Patent No. 6,110,378: Method of Using Novel Silico-titanates. Sandia National Laboratories, 2000.

(29) Anthony, R. G.; Philip, C. V.; Dosch, R. G. Waste Management 1993, 13, 503.

(30) Cherry, B. R.; Nyman, M.; Alam, T. M. J. Solid State Chem. 2004, 177, 2079-2093.

(31) Tripathi, A.; Medvedev, D. G.; Nyman, M.; Clearfield, A. J. Solid State Chem. 2003, 175, $72-83$. 
(32) Hobbs, D. T.; Barnes, M. J.; Pulmano, R. L.; Marshall, K. M.; Edwards, T. B.; Bronikowski, M. G.; Fink, S. D. Seperation Sci. Technol. 2005, 40, 3093-3111.

(33) Dosch, R. G. "RS-8232-2/50318: Use of titanates in decontamination of defense waste," Sandia National Laboratories,Albuquerque, NM. 1978.

(34) Behrens, E. A.; Sylvester, P.; Clearfield, A. Environ. Sci. Technol. 1998, 32, 101-107.

(35) Lehto, J.; Brodkin, L.; Harjula, R.; Tusa, E. Nuclear Technology 1999, 127, 81-87.

(36) Nyman, M. D.; Hobbs, D. T., U.S. patent application \#SD-7976: Hydrogen Peroxide modified sodium titanates with improved sorption capabilities. Sandia National Laboratories, submitted May 2005.

(37) Bonino, R.; Damin, A.; Ricchiardi, G.; Ricci, M.; Spano, G.; D'Aloisio, R.; Zecchina, A.; Lamberti, C.; Prestipino, C.; Bordiga, S. J. Phys. Chem. B. 2004, 108, 3573-3583.

(38) Bordiga, S.; Damin, A.; Bonino, F.; Ricchiardi, G.; Zecchina, A.; Tagliapietra, R.; Lanberti, C. Phys. Chem. Chem. Phys. 2003, 5, 4390-4393.

(39) Duff, M. C.; Hunter, D. B.; Hobbs, D. T.; Fink, S. D.; Dai, Z.; Bradley, J. P. Environ. Sci. Technol. 2004, 38, 5201-5207.

(40) Clearfield, A.; Lehto, J. J. Solid State Chem. 1988, 73, 98-106.

(41) Brinker, C. J.; Scherer, G. W. The Physics and Chemistry of Sol-gel Processing; Academic Press, Elsevier Science: San Diego, 1989.

(42) Bortun, A. I.; Bortun, L. N.; Poojary, D. M.; Xiang, O.; Clearfield, A. Chem. Mater. 2000, 12, 294-305.

(43) Zheng, Z.; Phillip, C. V.; Anthony, R. G.; Krumhansl, J. L.; Trudell, D. E.; Miller, J. E. Ind. Eng. Chem. Res. 1996, 35, 4246-4256.

(44) Burns, P. C.; Kubatko, K.; Sigmon, G.; Fryer, B. J.; Gagnon, J. E.; Antonio, M. R.; Soderholm, L. Angew. Chem. Int. Ed. 2005, 44, 2135-2139.

(45) Gogolev, A. V.; Shilov, V. P.; Pikaev, A. K. Mendeleev Commun. 1996, 127-128.

(46) Kubatko, K.; Helean, K. B.; Navrotsky, A.; Burns, P. C. Science 2003, 302, 1191-1193.

(47) Shilov, V. P.; Gogolev, A. V.; Pikaev, A. K. Mendeleev Commun. 1998, 220-222.

(48) Shilov, V. P.; Gogolev, A. V.; Pikaev, A. K. Radiochemistry 1998, 40, 321-325. 
Table 1. Summary of Synthesis Parameters for Peroxo-titanate Materials

\begin{tabular}{|c|c|c|c|c|c|c|c|}
\hline \multicolumn{8}{|c|}{ Post-synthesis peroxide treatment of Optima MST slurry } \\
\hline $\begin{array}{c}\text { Experiment } \\
\#\end{array}$ & $\mathrm{H}_{2} \mathrm{O}_{2}$ :Ti ratio & $\begin{array}{c}\mathrm{pH} \text { of } \mathrm{H}_{2} \mathrm{O}_{2} \\
\text { treatment }\end{array}$ & $\begin{array}{l}\text { Contact } \\
\text { Time }\end{array}$ & & justment & \multicolumn{2}{|c|}{$\begin{array}{c}\text { Product composition }^{5} \\
\text { Ti:Na molar ratio }\end{array}$} \\
\hline $1 \mathrm{P}$ & 3.0 & 2 & $24 \mathrm{~h}$ & \multicolumn{2}{|c|}{ no } & \multicolumn{2}{|r|}{17.3} \\
\hline $2 \mathrm{P}$ & 3.0 & 3 & $24 \mathrm{~h}$ & \multicolumn{2}{|c|}{ no } & \multicolumn{2}{|r|}{9.43} \\
\hline $3 \mathrm{P}$ & 3.0 & 4 & $24 \mathrm{~h}$ & \multicolumn{2}{|c|}{ no } & \multicolumn{2}{|r|}{5.63} \\
\hline $4 \mathrm{P}$ & 3.0 & 5 & $24 \mathrm{~h}$ & \multicolumn{2}{|c|}{ no } & \multicolumn{2}{|r|}{4.19} \\
\hline $5 \mathrm{P}$ & 3.0 & 6 & $24 \mathrm{~h}$ & \multicolumn{2}{|c|}{ no } & \multicolumn{2}{|r|}{3.38} \\
\hline $6 \mathrm{P}$ & 3.0 & 7 & $24 \mathrm{~h}$ & \multicolumn{2}{|c|}{ no } & \multicolumn{2}{|r|}{3.34} \\
\hline $7 \mathrm{P}$ & 3.0 & 8 & $24 \mathrm{~h}$ & \multicolumn{2}{|c|}{ no } & \multicolumn{2}{|r|}{2.87} \\
\hline $8 \mathrm{P}$ & 0.3 & 4 & $24 \mathrm{~h}$ & \multicolumn{2}{|c|}{ no } & \multicolumn{2}{|r|}{5.93} \\
\hline $9 \mathrm{P}$ & 1.0 & 4 & $24 \mathrm{~h}$ & \multicolumn{2}{|c|}{ no } & & 5.82 \\
\hline $10 \mathrm{P}$ & 6.0 & 4 & $24 \mathrm{~h}$ & & & & 5.83 \\
\hline $11 \mathrm{P}$ & 3.0 & 4 & $4 \mathrm{~h}$ & & & & 6.08 \\
\hline $12 \mathrm{P}$ & 3.0 & 4 & $96 \mathrm{~h}$ & & & & 4.97 \\
\hline $13 \mathrm{P}$ & 3.0 & 7 & $24 \mathrm{~h}$ & & H 2) & & 3.45 \\
\hline $14 \mathrm{P}$ & 3.0 & 7 & $24 \mathrm{~h}$ & & 4) & & 3.39 \\
\hline $15 \mathrm{P}$ & $6.0^{1}$ & 4 & $24 \mathrm{~h}$ & & & & 6.06 \\
\hline & & & & Isopropanol- & & & \\
\hline Experiment & $\mathrm{H}_{2} \mathrm{O}_{2}$ :Ti ratio & Neutral/ & Contact & final $\mathrm{pH}$ & owder or slurry & Pro & t composition ${ }^{5}$ \\
\hline \# & & acidic $^{2}$ & Time & adjustment & & $\begin{array}{c}\mathrm{wt} \% \\
\text { volatile }^{4}\end{array}$ & Ti:Na molar ratio) \\
\hline 1I & 3.0 & neutral & $24 \mathrm{~h}$ & no & Powder & 30 & 2.12 \\
\hline 2I & 3.0 & neutral & $96 \mathrm{~h}$ & no & Powder & 28 & 2.13 \\
\hline $3 \mathrm{I}$ & 0.3 & neutral & $24 \mathrm{~h}$ & no & Powder & 48 & 1.96 \\
\hline $4 \mathrm{I}$ & 1.0 & neutral & $24 \mathrm{~h}$ & no & Powder & 35 & 1.64 \\
\hline $5 \mathrm{I}$ & 6.0 & neutral & $24 \mathrm{~h}$ & no & Powder & 30 & 2.05 \\
\hline $6 \mathrm{I}$ & 3.0 & acidic & $24 \mathrm{~h}$ & no & Powder & 29 & 2.07 \\
\hline $7 \mathrm{I}$ & 3.0 & acidic & $4 \mathrm{~h}$ & no & Powder & 32 & 1.60 \\
\hline $8 \mathrm{I}$ & 3.0 & neutral & $24 \mathrm{~h}$ & yes (pH 2) & Powder & 32 & 40.8 \\
\hline 9I & 3.0 & neutral & $24 \mathrm{~h}$ & yes $(\mathrm{pH} 4)$ & Powder & 32 & 23.1 \\
\hline $10 \mathrm{I}$ & 3.0 & Neutral & $24 \mathrm{~h}$ & No & Slurry & 32 & 2.17 \\
\hline $11 \mathrm{I}$ & 3.0 & Acidic & $24 \mathrm{~h}$ & No & Slurry & 36 & 1.94 \\
\hline $12 \mathrm{I}$ & 3.0 & Neutral & $24 \mathrm{~h}$ & Yes (pH 4) & Slurry & 30 & 22.4 \\
\hline $13 \mathrm{I}$ & 3.0 & acidic & $24 \mathrm{~h}$ & Yes ( $\mathrm{pH} 4)$ & slurry & 35 & 36.5 \\
\hline & & & & Aqueous-pe & & & \\
\hline Experiment & Aqueous & Powder or & Final $\mathrm{pH}$ & & aditions & Pro & et composition ${ }^{5}$ \\
\hline \# & $\begin{array}{l}\text { solution for } \\
\text { synthesis }\end{array}$ & slurry & adjustment & & & $\begin{array}{c}\text { wt } \% \\
\text { volatile }^{4}\end{array}$ & Ti:Na molar ratio \\
\hline $1 \mathrm{~A}$ & $3 \mathrm{M} \mathrm{NaOH}$ & powder & no & & & 23 & 1.67 \\
\hline $2 \mathrm{~A}$ & $2 \mathrm{M} \mathrm{NaOH}$ & powder & no & & & 24 & 1.75 \\
\hline $3 \mathrm{~A}$ & $1 \mathrm{M} \mathrm{NaOH}$ & powder & no & & & 26 & 1.55 \\
\hline $4 \mathrm{~A}$ & $3 \mathrm{M} \mathrm{NaOH}$ & powder & yes (pH 2) & & & 43 & 27.1 \\
\hline $5 \mathrm{~A}$ & $3 \mathrm{M} \mathrm{NaOH}$ & powder & yes (pH 4) & & & 48 & 7.37 \\
\hline $6 \mathrm{~A}$ & $3 \mathrm{M} \mathrm{NaOH}$ & powder & no & $1 / 2$ concentratic & & 28 & 1.93 \\
\hline $7 \mathrm{~A}$ & $3 \mathrm{M} \mathrm{NaOH}$ & powder & no & $\mathrm{TiCl}_{4}$ in place & se addition of reagents ${ }^{3}$ & 33 & 1.55 \\
\hline $8 \mathrm{~A}$ & $3 \mathrm{M} \mathrm{NaOH}$ & powder & no & $\mathrm{TiCl}_{4}$ in place & al addition of reagents ${ }^{3}$ & 36 & 1.58 \\
\hline $9 \mathrm{~A}$ & $3 \mathrm{M} \mathrm{NaOH}$ & powder & no & $1 / 10^{\text {th }}$ concen & base & 53 & 1.83 \\
\hline $10 \mathrm{~A}$ & $3 \mathrm{M} \mathrm{NaOH}$ & slurry & no & & & 25 & 2.07 \\
\hline $11 \mathrm{~A}$ & $3 \mathrm{M} \mathrm{NaOH}$ & slurry & yes (pH 4) & & & 25 & 6.68 \\
\hline $12 \mathrm{~A}$ & $3 \mathrm{M} \mathrm{NaOH}$ & slurry & no & Second post-s & ide treatment (see text) & 24 & 2.04 \\
\hline $13 \mathrm{~A}$ & $3 \mathrm{M} \mathrm{NaOH}$ & slurry & yes (pH 4) & Second post-s & ide treatment (see text) & 29 & 5.79 \\
\hline $14 \mathrm{~A}$ & $1 \mathrm{M} \mathrm{HNO}_{3}$ & Slurry & No & & & 55 & 23.2 \\
\hline $15 \mathrm{~A}$ & $\begin{array}{c}1 \mathrm{M} \mathrm{HNO}_{3} \& \\
\mathrm{NaNO}_{3}\end{array}$ & Slurry & No & $\begin{array}{l}2 \mathrm{M} \mathrm{NaOH} \text { ad } \\
\text { text) }\end{array}$ & ate titanate product (see & 35 & 3.16 \\
\hline $16 \mathrm{~A}$ & $1 \mathrm{M} \mathrm{HNO}_{3}$ & Slurry & Yes (pH 4) & & & 40 & 46.5 \\
\hline $17 \mathrm{~A}$ & $\begin{array}{l}1 \mathrm{M} \mathrm{HNO}_{3} \\
\& \mathrm{NaNO}_{3}\end{array}$ & slurry & Yes (pH 4) & & & 34 & 5.51 \\
\hline
\end{tabular}

${ }^{1}$ This preparation employed 2 sequential 24-h contacts of MST with hydrogen peroxide at a mole ratio of 3:1.

${ }^{2} 2.2$ grams water $/ \mathrm{H}_{2} \mathrm{O}_{2}$ add to alcohol solution for hydrolysis and condensation of $\mathrm{Na}$ and Ti alkoxides. Acidic refers to $0.1 \mathrm{M}$ nitric acid solution (see text)

${ }^{3}$ Normal addition: Ti added to base, followed by addition of peroxide. Inverse addition: Ti added to peroxide, followed by addition of base.

${ }_{5}^{4}$ wt \% volatile determined by TGA weight loss of volatile species of dry powder $\left(\mathrm{OH}, \mathrm{H} 2 \mathrm{O}, \mathrm{H}_{2} \mathrm{O}_{2}, \mathrm{H}_{3} \mathrm{O}^{+}, \mathrm{H}_{2} \mathrm{O}_{2}, \mathrm{HOO}^{-} \mathrm{O}_{2}{ }^{2-}\right.$, etc. $)$

${ }^{5}$ Composition for dry powder, in the case of a slurry product 
Table 2. Composition of Simulated Waste Solution

\begin{tabular}{|c|c|c|}
\hline Component & Target Concentration & Measured Concentration $^{\mathrm{a}}$ \\
\hline $\mathrm{NaNO}_{3}$ & $2.60 \mathrm{M}$ & $2.44(0.24) \mathrm{M}$ \\
\hline $\mathrm{NaOH}$ & $1.33 \mathrm{M}$ & $1.36(0.14) \mathrm{M}$ \\
\hline $\mathrm{Na}_{2} \mathrm{SO}_{4}$ & $0.521 \mathrm{M}$ & $0.551(0.055) \mathrm{M}$ \\
\hline $\mathrm{NaAl}(\mathrm{OH})_{4}$ & $0.429 \mathrm{M}$ & $0.503(0.050) \mathrm{M}$ \\
\hline $\mathrm{NaNO}_{2}$ & $0.134 \mathrm{M}$ & $0.116(0.012) \mathrm{M}$ \\
\hline $\mathrm{Na}_{2} \mathrm{CO}_{3}$ & $0.0260 \mathrm{M}$ & $0.016(0.010) \mathrm{M}$ \\
\hline Total Na & $5.6 \mathrm{M}$ & $5.2(0.52) \mathrm{M}$ \\
\hline Total Sr & $0.6 \mathrm{mg} \mathrm{L}^{-1}$ & $0.484(0.032) \mathrm{mg} \mathrm{L}^{-1}$ \\
\hline${ }^{85} \mathrm{Sr}$ & $\geq 1000 \mathrm{dpm} \mathrm{mL}^{-1}$ & $1.65 \times 10^{5}\left(3.22 \times 10^{3}\right) \mathrm{dpm} \mathrm{mL}^{-1 \mathrm{~b}}$ \\
\hline Total $\mathrm{Pu}$ & $0.2 \mathrm{mg} \mathrm{L}^{-1}$ & $0.218(0.013) \mathrm{mg} \mathrm{L}^{-1}$ \\
\hline${ }^{237} \mathrm{~Np}$ & $0.5 \mathrm{mg} \mathrm{L}^{-1}$ & $0.461(0.090) \mathrm{mg} \mathrm{L}^{-1}$ \\
\hline Total U & $10 \mathrm{mg} \mathrm{L}^{-1}$ & $9.55(0.33) \mathrm{mg} \mathrm{L}^{-1}$ \\
\hline
\end{tabular}

Table 3. BET surface area and normalized $\mathrm{Sr}, \mathrm{Pu}$ and $\mathrm{Np} \mathrm{DFs}^{1}$ for selected peroxo-titanate samples.

\begin{tabular}{|c|c|c|c|c|}
\hline Sample ID & $\begin{array}{c}\text { Surface area } \\
\left(\mathrm{m}^{2} / \mathrm{g}\right)\end{array}$ & $\begin{array}{c}\text { Normalized Sr } \\
\text { DF }\end{array}$ & $\begin{array}{c}\text { Normalized Pu } \\
\text { DF }\end{array}$ & $\begin{array}{c}\text { Normalized } \\
\text { Np DF }\end{array}$ \\
\hline 1A & 73 & 4.64 & 1.25 & 0.91 \\
\hline 2A & 54 & 6.27 & 1.85 & 0.91 \\
\hline 5A & 251 & 6.25 & 4.16 & 3.46 \\
\hline 6A & 49 & 2.00 & 1.06 & 0.91 \\
\hline 9A & 46 & 2.14 & 1.34 & 1.06 \\
\hline Baseline MST & 22.3 & 1 & 1 & 1 \\
\hline 14P-LS1 & 106 & 5.00 & 26.5 & 1.09 \\
\hline 14P-LS2 & 176 & 4.64 & 23.5 & 1.31 \\
\hline 14P-LS3 & 178 & 4.72 & 26.9 & 1.43 \\
\hline
\end{tabular}

${ }^{T}$ Normalized $D F$ values reported for 4 hour contact time with stimulant, normalized to

baseline MST (Optima Batch \#00-QAB-417)

${ }^{2}$ Optima Batch \#00-QAB-417 


\section{Figure Captions:}

Figure 1. Scanning electron micrographs of: (A) Peroxide-treated MST. (B) Peroxo-titanate from the isopronaol-peroxide synthesis. (C) Peroxo-titanate from basic aqueous-peroxide synthesis. D. Peroxotitanate from acidic aqueous-peroxide synthesis.

Figure 2. (A) Transmission electron micrograph. (B) high-resolution transmission electron micrograph of peroxo-titanate sorbent from the basic aqueous-peroxide synthesis; showing the fibrous morphology and the $\sim 7-8 \AA$ layers.

Figure 3. Thermogravimetric-differential thermal analysis (TGA-DTA) of: (A) MST and peroxide-treated MST. (B) Peroxo-titanate from basic aqueous-peroxide synthesis, and peroxo-titanate from basic aqueousperoxide synthesis with post-synthesis acidification. (C) Peroxo-titanate from isopropanol-peroxide synthesis, and peroxo-titanate from isopropanol-peroxide synthesis with post-synthesis acidification.

Figure 4. Summary of peroxo-titanate decontamination factors (DF) for strontium, plutonium and neptunium normalized to DF values for baseline monosodium titanate (red line at unity in each graph). The peroxide-treated MST are the yellow bars, peroxo-titanates from the isopropanol-peroxide synthesis are represented by green bars, and the peroxo-titanates from the aqueous-peroxide route are blue bars.

Figure 5. Bar graph comparing $\mathrm{Sr}, \mathrm{Pu}$, and $\mathrm{Np}$ decontamination factors (DF) of the best two peroxotitanate sorbents for each of the three synthetic routes. Standard error is $\pm 5 \%$ for each measurement.

Figure 6. Plot of concentrations of $\mathrm{Sr}, \mathrm{Np}$ and $\mathrm{Pu}$ in Savannah River Site simulant with respect to time, in contact with sorbents. These graphs compare the performance of several dry-powder peroxo-titanates to that of baseline MST slurry. The control is the simulant without added titanate sorbent. Standard error is $5 \%$ for each measurement.

Figure 7. Plot of concentrations of $\mathrm{Sr}, \mathrm{Np}$ and $\mathrm{Pu}$ in Savannah River Site simulant with respect to time, in contact with MST slurry and peroxide-treated MST slurry, at two different sorbent concentrations. 
Figure 1
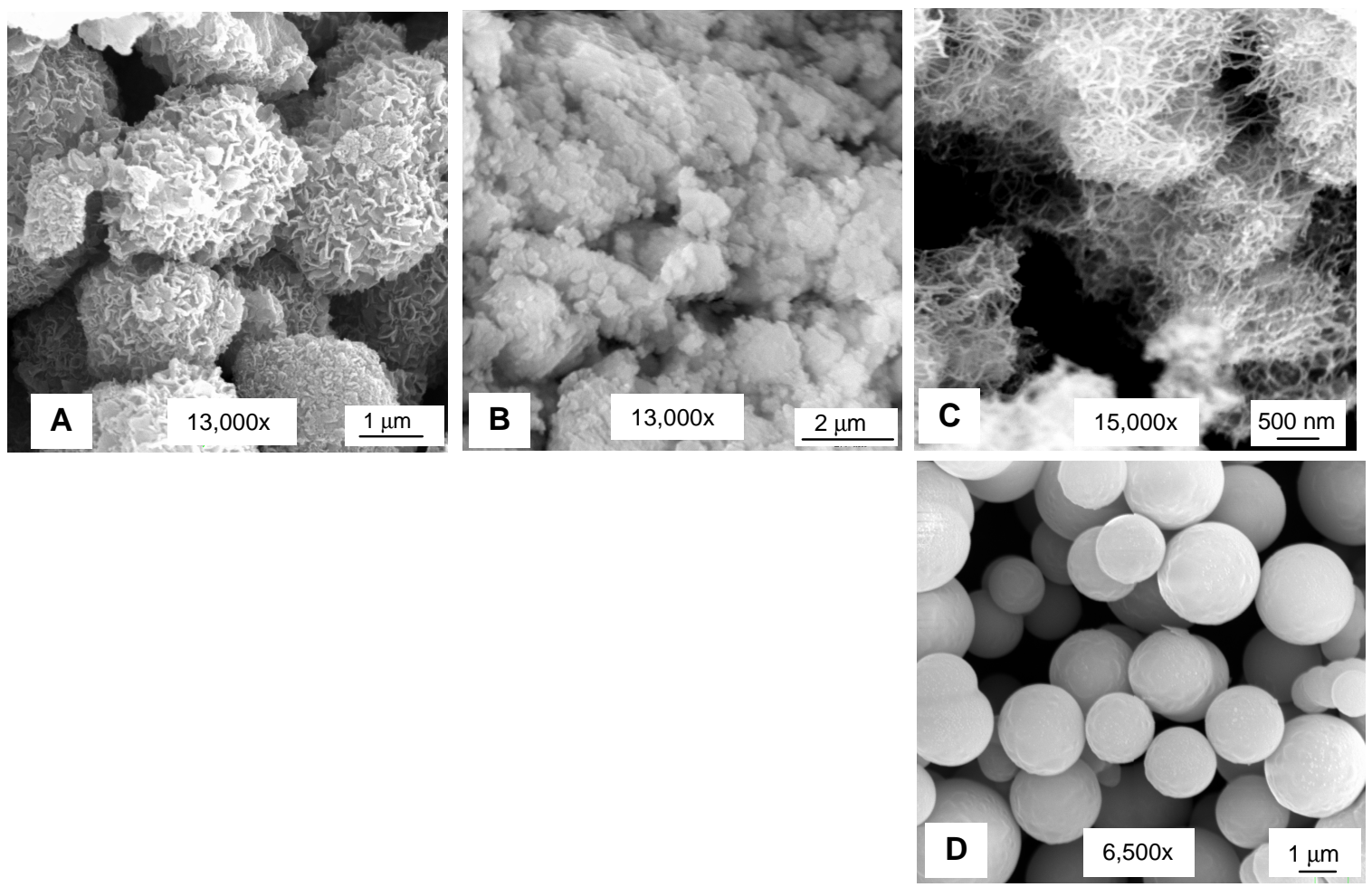

Figure 2
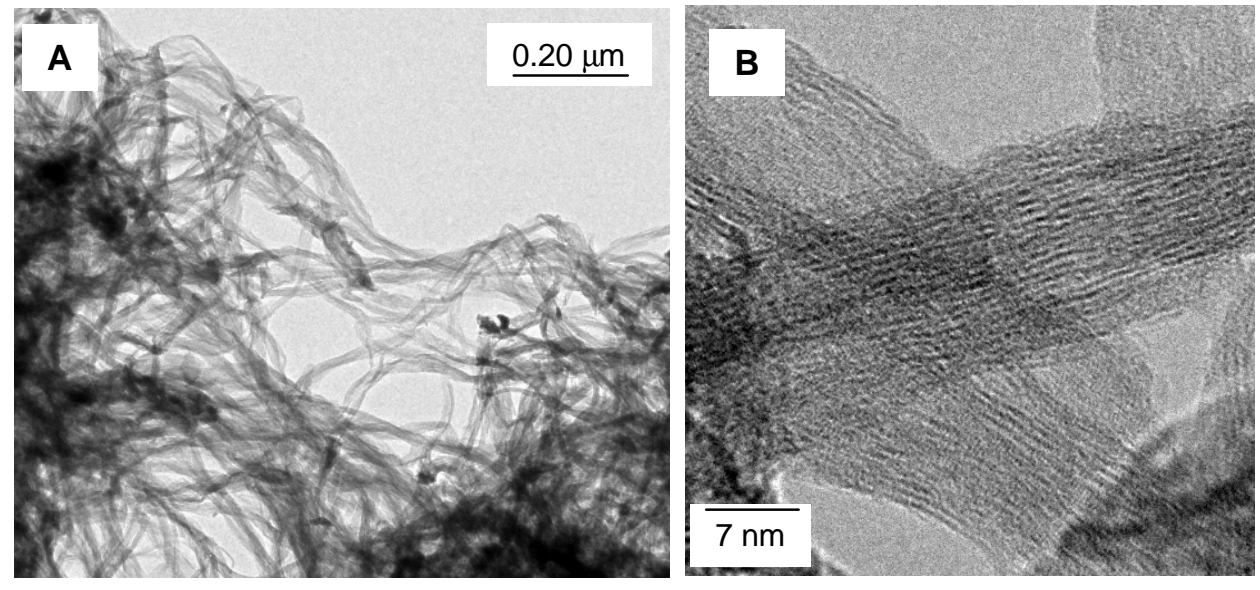
Figure 3
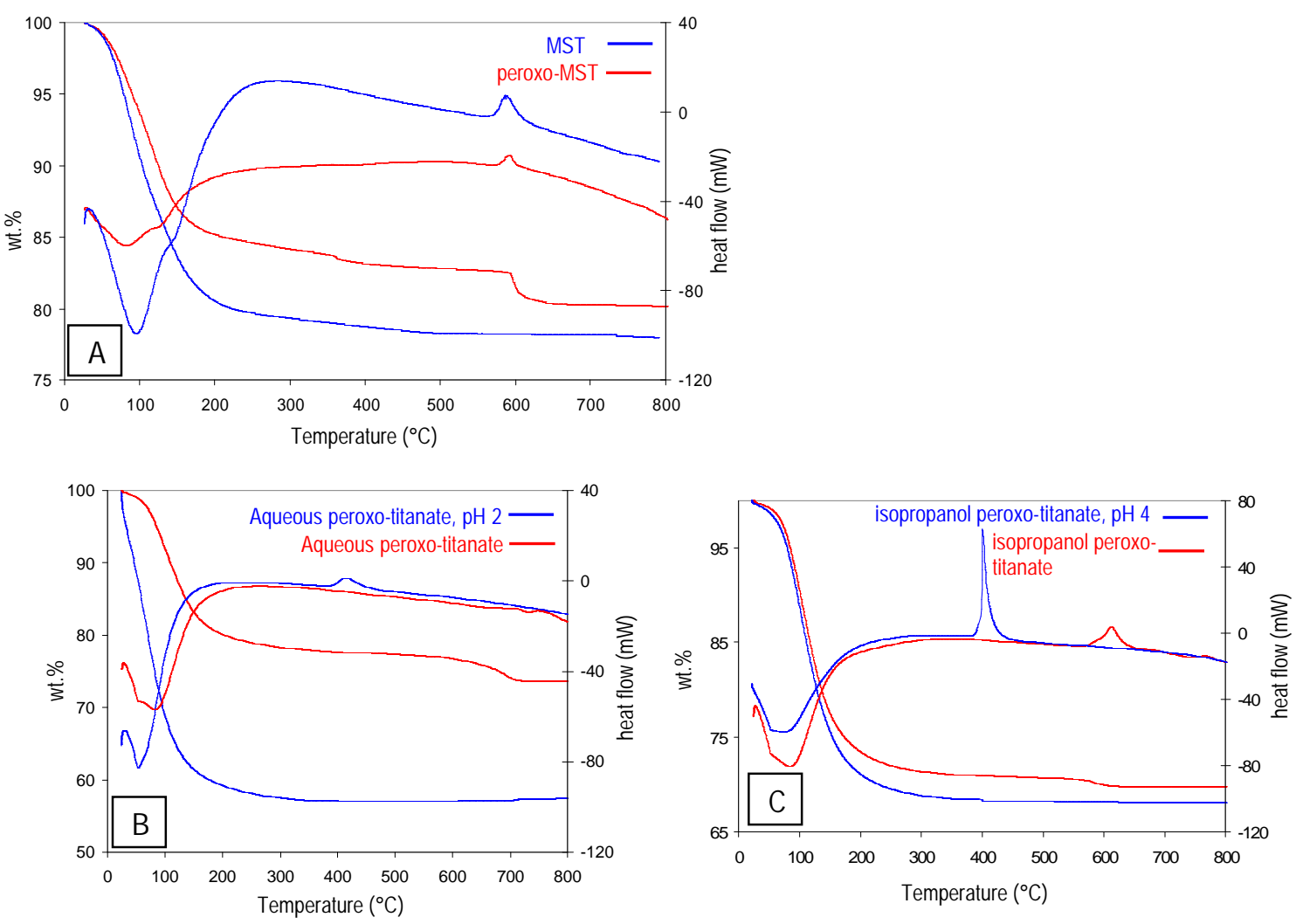
Figure 4
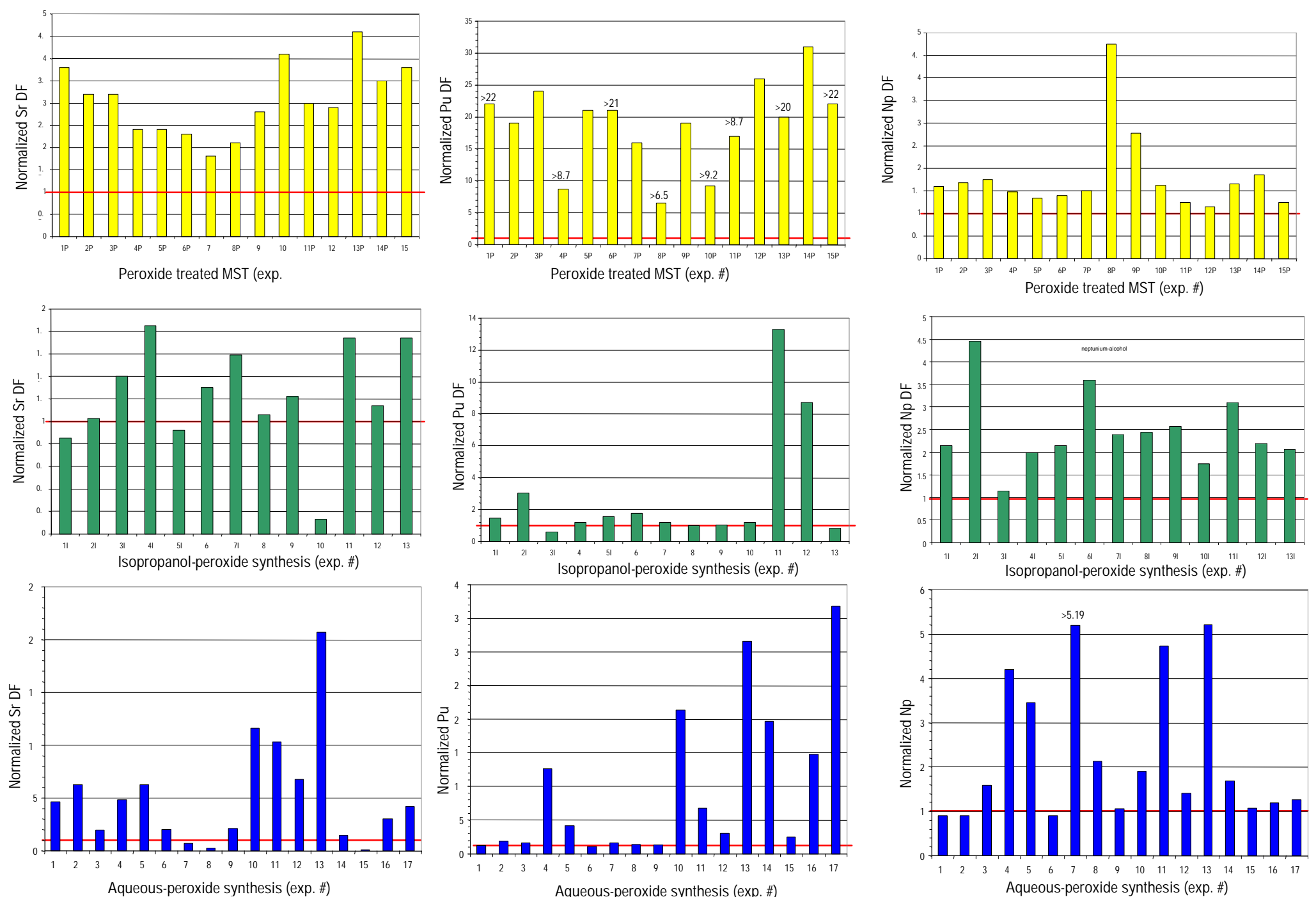


\section{Figure 5}

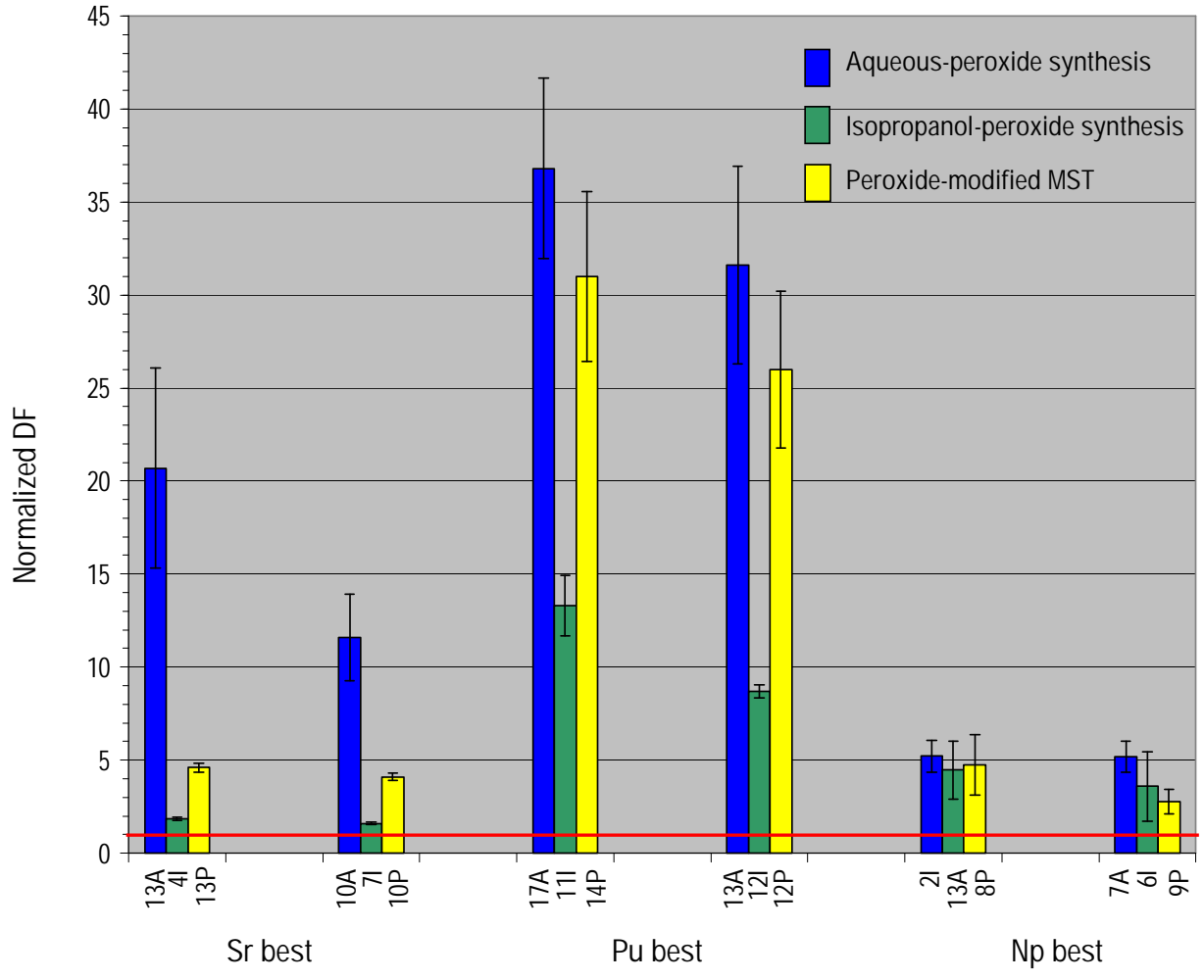


Figure 6
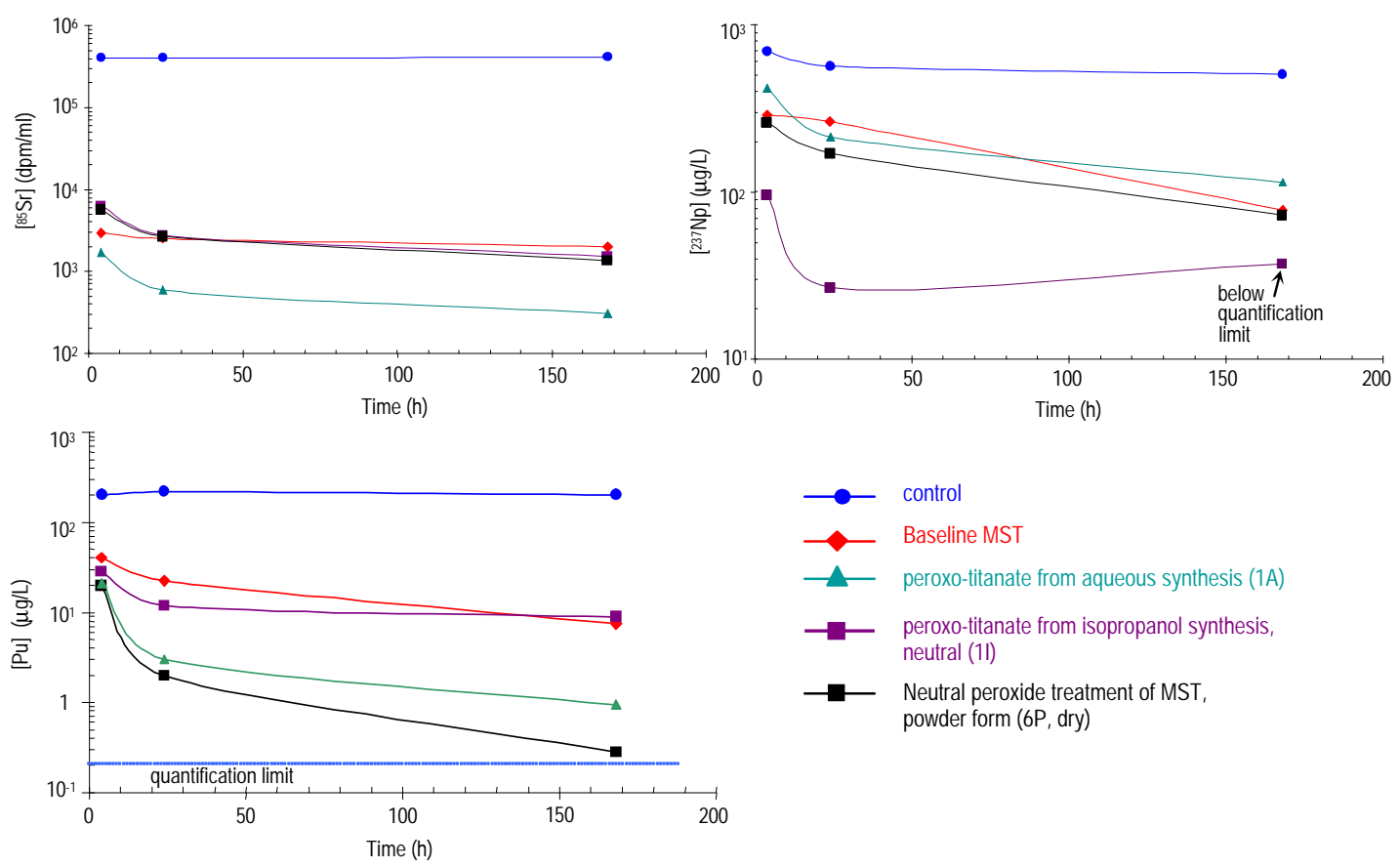

$\longrightarrow$ control

$\_$Baseline MST

$\longrightarrow$ peroxo-titanate from aqueous synthesis $(1 \mathrm{~A})$

- peroxo-titanate from isopropanol synthesis, neutral (1I)

$\longrightarrow$ Neutral peroxide treatment of MST, powder form (6P, dry)

Figure 7
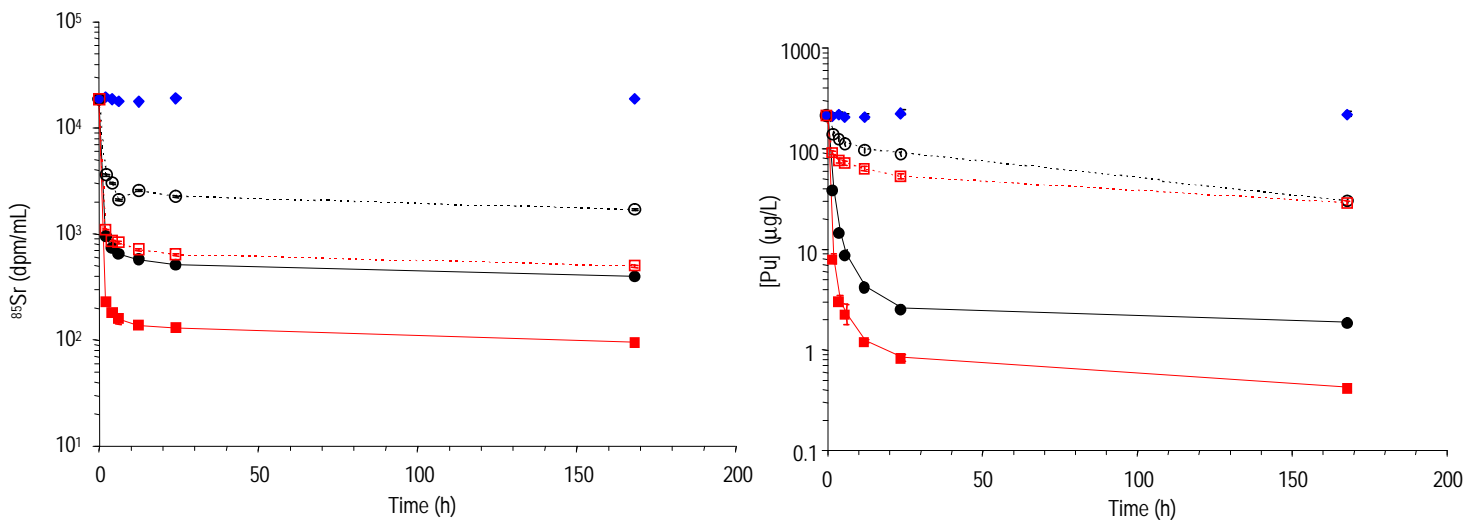

- Contro

- $0.1 \mathrm{~g} / \mathrm{L}$ peroxide-treated MST

..- $0.1 \mathrm{~g} / \mathrm{L}$ baseline MST

- $0.2 \mathrm{~g} / \mathrm{L}$ peroxide-treated MST ...ي $0.2 \mathrm{~g} / \mathrm{L}$ baseline MST 
TOC graphic

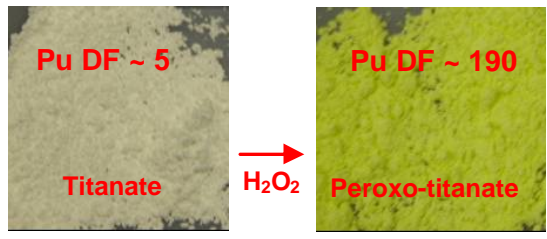

Sodium titanates are selective sorbents for radionuclides including ${ }^{90} \mathrm{Sr}$ and actinides. Modification or synthesis of sodium titanates with hydrogen peroxide creates a new class of peroxo-titanate sorbents. Peroxo-titanates made by a variety of synthetic routes exhibit universally enhanced selectivity and kinetics for sorption of hazardous waste metals. 